\title{
Leitura e Escrita
}

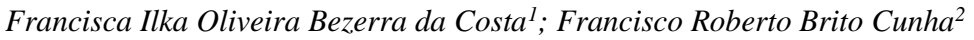

\begin{abstract}
Resumo: Este Artigo discute as teorias de Paulo Freire, Luiz Carlos Cagliari, Piaget e Vygotsky, à partir de uma análise das referidas teorias, e à luz das dificuldades e deficiências que os alunos de rede pública do ensino fundamental apresentam em relação a leitura e a escrita. Entende-se aqui, que a leitura é um processo que envolve outras habilidades além da decodificação. A leitura é um processo linguístico que acompanha o desenvolvimento da própria linguística seguindo o processo ascendente, descendente e interativo. Pode-se dizer que o significado que uma leitura tem para o leitor, é uma tradução do significado que o autor quis lhe dar, mais uma construção que envolve o texto, os conhecimentos prévios de leitura, que o aborda e seus objetivos, de acordo com os pensadores o ensino da língua portuguesa deve desenvolver no aluno a capacidade de compreender o texto como uma atividade necessária ao universo da vida social e escolar estabelecendo relação entre leitura de códigos e leitura de mundo. Para reverter o quadro apresentado do baixo índice de aprendizagem em relação aos estudos realizados, o professor deve ser um mediador que desenvolva no educando o senso crítico e sua maturidade respeitando a individualidade e a necessidade da realidade de cada um em relação ao ritmo de aprendizagem traçando caminhos que leve o educando a ser livre de preconceitos, respeitando as diversidades étnicas e variedades linguísticas. Entende-se que não desenvolvendo bons leitores, limitando-se as possibilidades de leitura de mundo quanto a realidade social. Constatou-se que a sociedade carece de profissionais competentes e compromissados que desenvolvam suas competências e habilidades, na consciência do seu papel como agentes transformadores da sociedade.
\end{abstract}

Palavra-chave: Leitura; Escrita; Aprendizagem

\section{Reading and writing}

\begin{abstract}
This article discusses the theories of Paulo Freire, Luiz Carlos Cagliari, Piaget and Vygotsky, based on an analysis of these theories, and in light of the difficulties and deficiencies that the public elementary school students present in relation to reading and the writing. It is understood here that reading is a process involving other skills than decoding. Reading is a linguistic process that accompanies the development of linguistics itself following the ascending, descending and interactive process. It can be said that the meaning that a reading has for the reader is a translation of the meaning that the author wanted to give it, a construction that involves the text, the previous reading knowledge, which addresses it and its objectives, according to the thinkers the teaching of the Portuguese language should develop in the student the ability to understand the text as an activity necessary to the universe of social and school life establishing relationship between reading of codes and reading the world. In order to revert the presented table of the low learning index in relation to the studies carried out, the teacher must be a mediator who develops in the student the critical sense and its maturity respecting the individuality and the necessity of the reality of each one in relation to the rhythm of learning tracing Ways that lead the learner to be free of prejudice, respecting ethnic diversity and linguistic varieties. It is understood that not developing good readers, limiting the possibilities of reading the world as social reality. It was found that society lacks competent and committed professionals who develop their skills and abilities, in the awareness of their role as transforming agents of society.
\end{abstract}

Keyword: Reading; Writing; Learning

\footnotetext{
${ }^{1}$ Mestranda em Ciências da Educação pela Anne Sullivan University. Contato: francisca_ilka@hotmail.com;

${ }^{2}$ Graduação em Psicologia pela Universidade de Fortaleza. Mestre em Educação em Saúde pela Universidade de Fortaleza. Professor Assistente de Psicologia da Educação na Universidade Regional do Cariri - URCA. E-mail: frobertobrito@ @otmail.com.
} 


\title{
Introdução
}

A pesquisa tem como objetivo esclarecer as causas da deficiência na aprendizagem em relação a leitura e a escrita dos alunos do $5^{\circ}$ ano da escola pública do ensino fundamental que apesar do índice de aprovação ter se elevado, constatou-se uma quantidade significativa de alunos ainda apresentam dificuldades de aprendizagem em relação ao assunto supracitado.

Esse trabalho tem como objetivo promover o sucesso escolar processando um método de ação e reflexão eficaz que favoreça uma linha de ação pedagógica que respeite os diversos níveis e ritmos de desenvolvimento de aprendizagem.

Sabe-se que as capacidades cognitivas humanas são fundadas biologicamente e que elas possuem sim suas limitações. As capacidades cognitivas são as energias mentais disponíveis nos indivíduos, ativados e desenvolvidos nos indivíduos, ativados e desenvolvidos no processo de ensino em estreita relação com os conhecimentos.

Buscando explicações mais consistentes (fontes de pesquisa e reflexão) ao instigar o mundo do aluno e suas peculiaridades e extrair como se dá o uso da oralidade, leitura e escrita em seu cotidiano, tal mundo com suas vivencias mostra-se rico, em experiências como mostra Freire (2002, P.S) no texto seguinte:

\begin{abstract}
Ao ir escrevendo este texto, ia tomando distância dos diferentes momentos em que o ato de ler se veio dando na minha experiência existencial, primeiro a leitura do mundo, de pequeno em que me movia; depois a leitura de palavra que nem sempre, ao longo da minha escolarização, foi a leitura da palavra mundo.
\end{abstract}

Os textos, as palavras e as letras daquele contexto - em cuja percepção experimentava e quanto mais o fizesse, mais aumentava a capacidade de perceber - se encarnavam numa série de coisas, de objetos, de sinais cuja compreensão eu ia aprendendo no meu trato com eles, na minha relação com meus irmãos mais velhos e com meus pais.

Os "textos", as "palavras" e as letras daquele contexto se encarnavam no canto dos pássaros o do sanhaçu, o do olhar pro - caminho - quem vem o bem-te-vi, o do sabiá; na dança da copa das árvores separados por fortes ventanias que anunciavam tempestades, trovões, relâmpagos, ás aguas da chuva brincando de geografia; inventando lago, ilhas, rios, riachos.

Os "textos", as "palavras", as "letras" daquele contexto se encarnavam no assoleio do vento, nas nuvens do céu, nas suas cores, os seus movimentos; na cor das folhagens na forma das folhas no cheiro das flores - das rosas, dos jasmins - no corpo das arvores, na casa dos frutos, na tonalidade diferente de cores de um mesmo fruto, na tonalidade diferente de cores de um mesmo fruto em momentos distintos. $\mathrm{O}$ verde da 
manga espada verde, o verde da manga-espada inchada; $\mathrm{O}$ amarelo esverdeado da mesma manga amadurecendo, as pintas negras mais além de madura.

A relação entre estas cores, o desenvolvimento do fruto, a sua resistência à nossa manipulação o seu gasto.

Foi nesse tempo possivelmente, que eu, fazendo e vendo fazer, aprendi a significação da ação de amolengar.

A construção deste Artigo está no fato de abordar uma problemática refletida na escola a partir de uma ótica social, buscando raízes de tais deficiência da leitura no dia a dia do aluno e junto com ele encontrar as melhores formas de recriar o processo de aprendizagem da leitura incrementando a sua realidade na sala de aula. E no convívio com aqueles alunos em dificuldade que podemos encontrar respostas, soluções para um direcionamento de novas ações do professor, adaptando-se a realidade social dos alunos.

Verificando a importância da leitura no seu cotidiano constata-se a necessidade de levar esse cotidiano para sala de aula, dando uma nova dimensão a leitura escolar e também ao mundo. Pode-se dizer que a estrutura composicional, os recursos linguísticos da construção dos testos a da capacidade de ler com compreensão.

Já a fala e a escrita são duas modalidades diferentes da língua, pois falamos um jeito e escrevemos de outro, sendo que na língua escrita há mais exigências em relação as regras gramaticais. A escrita não se reflete a fala individual de ninguém e de nenhum grupo social, por essa razão a fala e a escrita exigem conhecimentos diferentes.

Segundo Cagliari (1991), o problema da alfabetização é sem dúvida importante e gravíssimo, já que há muitas décadas de observam as mesmas dificuldades de aprendizagem e as inúmeras reprovações de alunos não falantes da língua padrão. Admitir a variação linguística não resolve os problemas escolares dos alunos, mas sem isso se conhecerá muito pouco do que acontece numa sala de alfabetização.

O professor deve ser um mediador e facilitar a aprendizagem de forma dinâmica, usando estratégias que se adequem a necessidade e realidade de cada um. Trocando experiências, respeitando as variedades linguísticas, criando situações que desenvolvem o senso crítico do educando em relação a leitura e a escrita na interpretação de testos e levantando questionamentos capazes de leva-los a produzir seus próprios conhecimentos. 
Sabe-se que se vive num mundo de constantes mudanças econômicas, sociais, políticas e culturais, e que a informação possibilita ao indivíduo obter uma bagagem cultural adequada ao exercício de cidadania.

\section{Leitura e Escrita.}

De acordo com essa pesquisa foi constatado que a leitura antecede a escrita e que a criança ao entrar na escola já tem uma visão de mundo. Traz consigo um conhecimento prévio, cabendo ao educador ampliar esse conhecimento realizando a leitura contínua aproveitando a própria bagagem do educando que é baseado no estímulo, reforço e resposta que linguisticamente é adquirida com o convívio familiar e social que devem ser respeitadas, valorizadas e estimuladas pelos professores e também pela escola, respeitando as diferenças linguísticas e as diversidades sociais, trabalhando sempre a interdisciplinaridade, interação sempre buscando novos desafios atitudes e procedimentos.

Nessa concepção o ensino se dá de forma contextualizada e que o professor seja um mediador construtivista e sócio internacionalista, por que ele se preocupa em ensinar e aprender, fazendo sempre com que os alunos construam significados e significantes, dando-lhes a oportunidade no processo de construção desse conhecimento de cada um preparando o indivíduo para exercer a plena cidadania no mundo global.

Foi constatado que os autores têm pontos de visa semelhantes em relação ao aprendizado do aluno. Deve ser aproveitada toda a bagagem de conhecimentos prévios trazidos pelos alunos, ao ingresso na escola, como experiências vivenciadas, trabalhando o coletivo e o social do aluno.

O processo de ensino-aprendizagem se dá quando há uma interação entre professor e aluno caracterizando uma combinação de atividades entre ambos pelo estudo da disciplina sob a direção do professor que traça uma linha de ação que se vai atingindo progressivamente o desenvolvimento de suas capacidades mentais, o desenvolvimento de tais capacidades e o modo de ação é o principal objetivo do processo ensino-aprendizagem, assimilação de conhecimentos, hábitos e habilidades. 
Os referidos autores são semelhantes quando valorizam os conhecimentos prévios, quando trabalham as variedades linguísticas e quando dizem que a dificuldade do aprendizado está em o educador não conhecer a linguagem do aluno, que os conteúdos não são contextualizados e que a escola deve abrir um leque de oportunidade de conhecimento que não se limite à sala de aula mas coletivo desenvolvendo o senso crítico, valorizando esse aprendizado vivenciado, dando oportunidade e sentido a aprendizagem do aluno. Que o trabalho dos alunos seja monitorado, que avaliação seja continua, que o professor saiba valorizar o progresso dos alunos, saiba quanto e quais alunos estão em dificuldades em cada disciplina, conteúdo, que haja sempre coleta de dados, arquivos, relatórios sobre o desenvolvimento dos alunos e para detectar, diagnosticar e resolver o problema de leitura e escrita dos alunos do ensino fundamental.

\section{A Importância do Ato de Ler}

Conforme Freire (1992), a leitura do mundo precede sempre a leitura da palavra. O ato de ler se veio dando na sua experiência primeiro a "leitura" do mundo, do pequeno mundo em que mora depois a leitura da palavra que nem sempre ao longo de sua escolarização fora cultuada da palavra mundo na verdade aquele mundo especial se dava a ele como o mundo de suas primeiras leituras. Os "textos", as "palavras", as "letras" daquele contexto em cuja percepção experimentava a capacidade de perceber se encarnavam numa série de coisas e objetos, de sinais, cujas compreensão ia aprendendo no seu texto com eles, na sua relação com seus irmãos mais velhos e com seus país.

A leitura do seu mundo foi sempre fundamental para a compreensão do ato de ler, de escrever, ou reescrevê-lo, e transforma-lo através de uma prática consciente.

Quando o homem compreende sua realidade, pode levantar hipóteses sobre o desafio dessa realidade e processar soluções e assim, pode transforma-la e com seu trabalho pode criar em próprio; seu eu e suas circunstancias (FREIRE, 2002, p.30).

Essa pesquisa bibliográfica possibilita uma relação mais próxima de alunos e professores, a partir do conhecimento do dia a dia dos alunos com base em pesquisas e observações fortalecendo a relação família, escola, profissão, destacando a importância dessa 
proximidade para uma educação completa com base no exercício da leitura, pratica escolar, esta que entraria em sintonia com a vivencia dos alunos.

O fato de vivermos em sociedade, de estarmos em constante interação com os outros, afim de compreendermos a nós mesmos e a tudo que está a nossa volta, faz parte de um longo processo de internalização de formas culturais. Ao mesmo tempo em que originam. Também modificam nossos comportamentos, nossas concepções, nossa forma de tratar as pessoas, de emitir opiniões, em fim de processar, decifrar, desvendar, explicar e dar sentido ao mundo em que estamos inseridos. É com base nesse pressuposto que Paulo Freire afirma que a leitura do mundo precede a leitura de palavras e que a posterior leitura desta não pode preceder da leitura daquela. A escola deve preparar homens e mulheres em condições de uma melhor interação e participação nas transformações do seu universo.

\begin{abstract}
A escola deve ser um espaço permanente de discussão dos problemas relacionados à vida de pessoas. $\mathrm{O}$ ambiente escolar deve pensar alternativas ou superação das contradições apresentadas pela realidade. A escola tem a missão de pensar os contextos sociais (as desigualdades, o desemprego, o problema das minorias, a exclusão) enfim, a gama de problemas do mundo atual (FREIRE, 1992, p.50).
\end{abstract}

A pesquisa sobre as dificuldades do aprendizado as dificuldades do aprendizado da leitura e da escrita trará dados para uma compreensão de como o aluno aprende, o que é necessário para que ele aprenda e quais as repercussões deste aprendizado ou da sua ausência sobre as transformações sociais, por que vale o que está escrito, ou as letras e seus estilos.

Conforme Cagliari (1991), "para compreender o processo da leitura é preciso alguns aspectos básicos dos sistemas de escrita e, em particular do sistema alfabético que usamos. Todo sistema de escrita tem um aspecto funcional e um aspecto gráfico. A união desses dois aspectos é semelhante a união de significados e significante no signo linguístico, no qual primeiro refere-se ao sentido das palavras e o segundo aos sons".

Letras são caracteres do sistema alfabético de escrita. Os caracteres compõem um inventário fechado de sinais gráficos, junto com os acentos de pontuações e demais marcas dos sistemas de escrita. Isso significa que não pode inventar um novo caractere ou destruir um já existente. 
Ainda na concepção de Cagliari (1991), “a criança é um falante nativo de uma língua. E que desde o nascimento os indivíduos estão inseridos num ambiente e o entendimento se dá através de uma linguagem que possui características próprias especificas".

O aluno ao ingressar na escola, leva consigo a experiência adquirida no decorrer de sua trajetória de vida, a qual deve ser somada aos conhecimentos que irá aprender na escola, dessa forma ele irá tocando e adquirindo novas experiências com o professor e com os colegas. Esse processo deve ser contínuo, de forma que possa aproveitar todo o conhecimento prévio do aluno.

\section{Conceituando Leitura e Escrita}

Definir leitura e escrita não é tarefa fácil, pois se trata de áreas complexas e abrangentes. São vários os sentidos atribuídos ás ideias de leitura e escrita, podendo estes serem restritos ou amplos.

No sentido restrito da palavra, conforme Ximenes (2000, p.385), "escritura é a representação de palavras ou ideias por meio de letras ou sinais convencionais e constitui-se num sistema de intercomunicação humana por meio de signos visíveis visuais”.

De acordo com Cagliari (1991, p.152), “a leitura é uma atividade ligada essencialmente a escrita", assim o ato de decodificar um texto requer também o ato de decodificá-lo através de várias linguísticas. É de grande importância ressaltar que a leitura e a escritura são atividades fundamentadas para o desenvolvimento e formação do indivíduo, pois dentro e fora da escola por toda a vida, o domínio ou não de ambos facilitará ou não o crescimento intelectual.

A concepção de leitura encontrada junto aos professores de Ensino fundamental destacou as suas relações com as atividades de ensino. Criticam-se as concepções redutoras de leitura e delineiam-se concepções de cunho internacionalistas que orientam de forma objetiva e coerente o trabalho escolar.

As relações entre o pensamento e a ação colocam-se como elementos de diferentes procedências. Desta forma não há dúvidas sobre a formação de que maneira pela qual uma pessoa aprende.

O desenvolvimento das capacidades mentais e modos de ação e o principal objetivo do processo ensino-aprendizagem, assimilação de conhecimentos, habilidade e hábitos que a 
escola deve abrir um leque de conhecimentos sem ser limitado, isto é, na sala de aula, mais no coletivo desenvolvendo o senso crítico, valorizando esse aprendizado vivenciado dando oportunidade e sentido a aprendizagem do aluno. Que o trabalho seja monitorado, que a avaliação seja continua, que o professor saiba o progresso dos educandos e saibam quantas e quais alunos estão com dificuldades em cada disciplina/ conteúdo, que haja sempre coleta de dados, arquivos, relatórios, sobre o desempenho dos mesmos e possa detectar, diagnosticar, e resolver o problema dessa deficiência.

Para que haja aprendizagem satisfatória deve ser aproveitado a bagagem de conhecimentos prévios que eles trazem ao ingressar na escola, como experiências vivenciadas, trabalhando o coletivo e o social do aluno.

Constata-se que em cada área do conhecimento faz-se necessário a aplicação de métodos adequados e eficazes para aquisição dos objetivos.

Não há métodos únicos de ensino, mas uma variedade de métodos cuja escola depende dos conteúdos da disciplina das situações especificas e das características sócio culturais e de desenvolvimento mental dos alunos.

Segundo Paulo Freire, educador é aquele que além de ensinar aprende; educando é aquele que além de aprender ensina.

O processo de ensino-aprendizagem se dá quando há uma interação entre professor/aluno caracterizando uma combinação de atividade entre ambos pelo estudo da disciplina.

Para obter bons resultados tem que se fazer um bom planejamento, isto é, uma prévia do que desejamos realizar, e que exige uma organização das ações de forma que os objetivos propostos tenham condições de serem atingidos e com resultados positivos e que o mesmo é um processo organizado sujeito a mudanças, para que se possa promover sua execução visando resultado satisfatório.

Todas as nossas ações requerem uma reflexão, e que de modos, os planejamentos fazem parte de toda a vida. Os atos mais simples necessitam de uma ação pensada e planejada.

O professor tem que priorizar o diálogo que é indispensável no convívio escolar. No entanto, ele só pode acontecer quando as pessoas envolvidas se respeitam mutuamente. Nesse sentido, ele será um instrumento importante não apenas para que o aluno consiga esclarecer os 
conflitos e resolve-los, mas também para que possa interagir com os colegas e realizar aprendizagens.

A solidariedade também se constitui num valor que a escola deve trabalhar com seus educadores e que está intrinsicamente ligado aos outros valores já mencionados. Portanto, em se tratando de solidariedade deve-se levar os alunos a praticá-los e pensar sobre ela em conjunto com os outros valores. Oportunidades para tal prática é o que não falta no relacionamento indivíduo e escola.

Por exemplo, ao invés de incentivar a competição entre os alunos ou competição entre os alunos ou comparar os diversos desempenhos, é preferível fazer com que se ajudem mutuamente: aquele que se sabe pode explicar aquele que ainda não sabe, aquele que não sabe deve poder sentir-se à vontade para pedir ajuda, para perguntar sem temor. $\mathrm{O}$ aluno que apresenta dificuldades não deve ser zombado ou humilhado, antes deve ser incentivado por todos.

No mundo em que nos cabe reinventar, a escola não deve solucionar alguns problemas, como no passado, mas valorizar as diferenças, não domesticar para obediência, mas emancipar para a participação. Nesse contexto é de grande importância a contribuição trazida pelas teorias das inteligências múltiplas, que permite ver o aluno não apenas pela competência em escrever e contar, mas por uma diversidade de linguagem como: se expressar desde cedo, através das experiências de socializações que devem ser permitidas e estimuladas pelo professor e pela escola.

Trazer à reflexão situações em que a igualdade se impões como representante daquilo que é justo (como por exemplo, as regras de funcionamento de classe: todos devem igualmente cumpri-las).

As normas referentes a conduta dos alunos e ao que deles exigem ser claras e conhecida pelos alunos.

E devem apresentar os direitos e deveres desses educandos. Todavia, expor apenas verbalmente regras não é suficiente. É preciso explica-las de forma que possa haver uma boa assimilação. As normas de conduta não devem conter apenas deveres dos alunos, seus direitos devem também ser esclarecidos, tal procedimento fará com que os discentes saibam exatamente quando estão injustiçados e possam defender seus direitos e objetivos respeitando diferentes opiniões de pensamento, pois a sociedade precisa de pessoas conscientes, comprometidas, 
competentes que desenvolva suas potencialidades como educando sabendo da importância do seu papel como futuros cidadãos da sociedade.

De acordo com Cagliari (1991, p.152):

\begin{abstract}
A leitura é uma atividade ligada essencialmente a escrita, assim o ato de decodificar um texto requer também o ato de decodifica-lo através de várias linguagens. É de grande importância ressaltar que a leitura e a escrita são atividades fundamentais para o desenvolvimento e formação do indivíduo, pois dentro e fora da escola e por toda a vida, o domínio ou não de ambos facilitará ou não o crescimento intelectual.
\end{abstract}

Já a leitura, conforme Martins (2006) pode ser conceituada como sendo um processo de compreensão de expressões formais e simbólicas que também acontece por meio de diversos tipos de linguagens.

Os autores são semelhantes quando valorizam os conhecimentos prévios quando trabalham as variedades linguísticas e quando dizem que a dificuldade do aprendizado está no educador não conhecer a linguagem do aluno, que os conteúdos não são contextualizados e que a escola deve abrir um leque de oportunidades de conhecimentos que não se limite a sala de aula, mas no coletivo desenvolvendo o senso crítico, valorizando o aprendizado vivenciado, dando oportunidade e sentido a aprendizagem do aluno. Que o trabalho dos alunos seja monitorado, que avaliação seja continua, que o professor saiba valorizar o programa dos alunos, saiba quantos e quais alunos estão em dificuldade, em cada disciplina, conteúdo, que haja sempre coleta de dados, arquivos, relatórios sobre o desempenho dos alunos para detectar, diagnosticar e resolver o problema de leitura e escrita dos alunos do ensino fundamental.

\title{
História da Escrita
}

Escrita! A história da mais primitiva forma de escrita a PICTOGRAFIA da Suméria, do Antigo Egito, onde se desenvolvem sistemas de sinais para representar os objetos. Surgiram depois os IDEOGRAMAS (representando ideias) e LOGRAMAS (representando palavras). A escrita cuneiforme dos sumérios e os hieróglifos egípcios possuíam signos linguísticos complexos, é semelhança dos signos da escrita ideográfica ainda usada na leitura atual. Também entre os sumérios surgiu pela primeira vez o sistema de escrita baseada em 
silabogramas, isto é, sinais representativos de silabas. A partir daí não foi difícil chegar a escrita fonética, ou seja, aos alfabetos, em que cada letra representa em fonema (ROCHA, 2005).

Durante o II milênio a.C surgiram os alfabetos semíticos que deram origem aos alfabetos gregos e latim, que com pequenas modificações, perduram até os dias atuais.

\section{Desenvolvimento e Aprendizagem}

Piaget (1896-1980), o criador da epistemologia genética, dedicou-se a pesquisa epistemológica, com o propósito de responder a questão: Como se constrói o conhecimento? Ao estudar as origens do conhecimento nas crianças, concluiu que ele se forma aos poucos, graças a construção progênita do próprio sujeito no decorrer de uma atividade de adaptação.

Piaget deu muita importância ao caráter construtivo do desenvolvimento cognitivo na criança, reconhecer que o desenvolvimento intelectual é produto da própria atividade da criança que não para de estudar e de estruturar seu próprio conhecimento quanto mais percebe as coisas mais aprende.

É importante notar que apesar de ser considerado um dos maiores psicólogos do desenvolvimento, Piaget é um biólogo por formação e um epistemólogo por interesse, na sua concepção o desenvolvimento cognitivo é espontâneo e está ligado ao processo da embriogenese que refere ao sistema nervoso, aos desenvolvimentos cognitivo, é o resultado de uma interação de sujeito com o meio em que vive. E que assimilação depende de determinadas informações, que depende dos níveis de desenvolvimento.

Sabe-se que para conhecer um objeto é preciso agir sobre ele, modifica-lo, transformalo conhecendo o caminho e que compreendendo como o mesmo foi construído. Para Piaget as estruturas são a base do conhecimento e que o problema central do desenvolvimento é compreender a formação, elaboração, a organização, e o funcionamento das estruturas de natureza operativa.

As estruturas variáveis serão as formas de organização da atividade mental, por um lado, é do ponto de vista afetiva, por outro" (COOLL e GILLIERON, o desenvolvimento intelectual e a construção do pensamento racional. In: Piaget e a Escola de Genebra, 1987, p.36) 
Existem três estágios ou períodos de desenvolvimento que marcam o aparecimento de novas estruturas sucessivamente construídas.

- Período Sensório-motor do nascimento a um ano e meio de idade;

- Período da inteligência representativa, preparo e organização das operações concretas, compreende dois subperíodos:

- Representações pré-operatórios

$1^{\circ}$ Estágio - dos dois aos três e meio/ quatro anos;

$2^{\circ}$ Estágio - dos quatro aos cinco anos;

$3^{\circ}$ Estágio - dos cinco e meio ao sete/ oito anos.

- Operações concretas - dos sete aos onze/ doze anos

- O Período das operações formais - Construção das estruturas próprias (raciocínio hipotético dedutivo), que se divide em dois estágios;

- $1^{\circ}$ Estágio - aos onze/ doze anos;

- $2^{\circ}$ Estágio - até os quinze/ dezesseis anos;

Pode-se dizer que as ideias de Piaget estão presentes em diversos colégios do mundo todo e suas teorias buscam implantar nos espaços de aprendizagem, metodologia inovadoras e significativas que o educando seja um ser ativo, crítico e participativo.

Vygotsky estuda as funções psicológicas superiores (pensamento abstrato, raciocínio dedutivo, capacidade de planejamento, atenção, lembrança voluntária, memorização ativa, controle consciente do comportamento, etc.). No ponto de vista sócio histórica os mecanismos não são inatos, o conhecimento se dá por instrumentos e signos entre os indivíduos e o meio em que ele está.

O homem desde que nasce já faz parte de um grupo social e através dessa interação permanente vai se apropriando através do processo de internalização desses conhecimentos e produzindo outros. As relações do homem com o mundo são fundamentalmente mediadas por signos e instrumentos.

$\mathrm{Na}$ ontogênese, as relações medidas predominam sobre as relações diretas, que sofrem transformações no decorrer do desenvolvimento do indivíduo, tornando-se relações medidas.

Segundo Vygotsky (1989), o homem em sua ação, cria instrumentos e signos para transformar a natureza e a si mesmo, construindo a cultura. "O signo age como instrumento da atividade psicológica de maneira análoga ao papel de um instrumento no trabalho (p.59.60) 
Para Vygotsky o desenvolvimento das funções humanas se dá no processo interativo do homem com o mundo, isto é, do homem o meio que está inserido (com suas dimensões históricas e sociais.

O aprendizado se dá através de interações com o meio físico, social e histórico, os contextos sociais diferenciados e as possibilidades de interações propiciam processos diferenciados de aprendizagem, conhecimentos e formas de pensamento.

O desenvolvimento e o aprendizado são processos distintos, que interagem na medida em que o aprendizado, junto de interação social, e internalizando e organizando, estimulando processos de desenvolvimento. O processo de desenvolvimento é progredido de forma mais lenta após o aprendizado. Todo aprendizado é de fundamental importância para o processo de desenvolvimento cognitivo que se dar em parte por exemplo: nas fases iniciais da vida é determinado pelo processo de maturação do organismo.

Sabe-se que o processo cognitivo é fruto do aprendizado do indivíduo que se dá através de interação com o meio sociocultural, através da mediação. O processo de interação é condição para o funcionamento da sociedade.

\section{Psicologia do Desenvolvimento e Aprendizagem}

Os processos de desenvolvimento psicológicos ocorrem nas fases da infância e adolescência. A fase adulta é compreendida como uma fase de estabilidade psicológica, com ausência de mudanças e um processo de decadência.

Como explica Palácio (1995) os processos cesso de desenvolvimento estão relacionados a três grandes fatores: etapa de vida; circunstancias culturais, históricas e sociais de sua existência e experiências particulares de ada um, não generalizáveis para outras pessoas. O desenvolvimento e a aprendizagem estão relacionados as experiências coletivas. A aprendizagem e o saber de um grupo social são frutos de atividades cognitivas das gerações precedentes e da possibilidade de um conhecimento construído. Chama-se de ponto chave a interação com o conhecimento construído para reflexão sobre o desenvolvimento e aprendizagem de adultos. 
Ao se indagar sobre quais aspectos foram apropriados da teoria nas pesquisas realizadas no âmbito da psicologia e da educação.

Wascocelos $(1996,1997)$ afirma que até o início da década de 1980, a ênfase deu-se em relação aos estágios de desenvolvimento cognitivos; depois dessa época, o interesse vinculouse a concepção construtivista e internacionalista do desenvolvimento, principalmente a partir da divulgação das ideias psicolinguistas de Emília Ferreiro.

Mono (2003, p.120). Três deste bloco tiveram desenvolvimentos, mais expressivo com temas de investigação, levando em conta a temas de investigação, levando em conta a especificidade do fenômeno escolar. "A psicogênese de conceito de várias compôs de conhecimento, geralmente, conteúdos escolares; as situações de interação social de pares favoráveis a aprendizagem, a elaboração de uma teoria da aprendizagem”. Segundo a autora, há grande incidência de estudos, com base na psicogenética, na matemática, na escrita, nas ciências naturais, na educação moral e ética e nas ciências sociais.

É uma ferramenta muito importante que contribui para compreender melhor o processo do conceito de aprendizagem procurando as principais teorias explicar o que é aprender e a participação do aluno e do professor nesse processo.

Dizemos que ocorre aprendizagem significativa quando ocorre uma mudança de comportamento. Pode-se dizer que existem vários tipos de sujeitos no processo de aprendizagem. Uns são mais lógicos, outros são mais táteis, outros são mais cognitivas, outros são mais motores, etc.

Isto nos leva a teoria de Gardner, que propôs a teoria das inteligências múltiplas. Desta forma temos vários estilos de aprendizagem, o que diferem de vários tipos de ensino.

Nas universidades se constata muitos estilos de Técnicas de ensino mais de aprendizagem é muito pouca. $\mathrm{O}$ cérebro humano tem que criar várias conexões com o que aprendemos, quanto mais caminhos tenho para chegar a um determinado local, menos possibilidade tenho de me perder. 


\section{Diferenças entre Piaget e Vygotsky em Relação a Psicologia da Aprendizagem}

As teorias de Piaget buscam implantar nos espaços de aprendizagem uma metodologia inovadora que busca formar cidadãos criativos e críticos. De acordo com sua teoria o professo não deve apenas ensinar mais sem antes de tudo, orientar os educandos no caminho as aprendizagens autônomas.

“O principal objetivo da educação é criar indivíduos capazes de fazer coisas novas e não simplesmente repetir o que outras gerações fizeram”.

"As estruturas operatórias da inteligência não são inatas".

Piaget considera a criança como construtora de seu conhecimento através de sua interação com o meio.

Vygotsky entra som a questão da zona de desenvolvimento proximal seria o "espaço" entre o que a criança sabe e o que está a saber. Local este também que se refere a intervenção de um mediador que é o professor o mediador do conhecimento. Existem diferenças entre ambos, mas o importante é que cada um com suas teorias contribuíram significa mente para a formação de um sujeito autônomo, ativo na estruturação de seu conhecimento. Vygotsky é sócio internacionalista, construiu sua teoria tendo por base o desenvolvimento do indivíduo com resultado de um processo sócio histórico, enfatizando o papel da linguagem e da aprendizagem nesse desenvolvimento, sendo essa teoria considerada histórico social. Sua questão central é aquisição de conhecimento pela interação de sujeito com o meio.

Pode-se dizer que na concepção de Vygotsky, existe uma relação entre o pensamento e a linguagem os indivíduos dão significados a construção dos seus conhecimentos e a transmissão e o que se aprende na escola é diferente do que de aprende no dia a dia.

Piaget valorizava o incentivo da imaginação na educação através do convívio social, brincadeiras, contos. Vygotsky valorizava o conhecimento na educação, quanto mais conhecimento adquirido mais a criança os cria sua imaginação, e mais aumenta seus conhecimentos. Os dois psicólogos supracitados são cognitivos, internacionalistas e tem vários pontos em comum.

Para Vygotsky o desenvolvimento do pensamento vai do social para o individual. Segundo Piaget a criança passa por quatro etapas do desenvolvimento cognitivo, que são eles: Sensório-motor (0-2 anos); Pré-operatório (2-7 anos); Operatório concreto (7-11 anos); 
Operatório foral (12 anos em diante). Cada uma dessas etapas nos ajuda a entender o desenvolvimento de criança.

Consta-se no esquema de Piaget que o desenvolvimento do pensamento da criança "parte do pensamento não verbal à fala socializada e ao pensamento lógico, através do pensamento e da fala egocêntrica.

\section{Análise de Dados}

O trabalho foi feito visando um melhoramento no aprendizado, buscando prepará-lo para aprender a aprender e descobrir outras estratégias de aprendizagem procurando desenvolver e aprimorar suas capacidades intelectuais e saber usar essa aprendizagem fora e dentro dela. O professor para facilitar o aprendizado do aluno deve procurar estratégias que adequem a realidade da turma incentivando, motivando nas atividades aproveitando o conhecimento do aluno juntamente com o do professor procurando conhecer e criar conhecimentos para superar as deficiências e dificuldades da aprendizagem.

O educador não deve se basear-se em uma única metodologia. Deve-se usar uma postura de pluralidade buscando diversos métodos, e teoria principalmente dos autores supracitados, buscando desenvolver nos alunos suas competências e habilidades usando métodos eficazes que possa ajudar aos alunos no decorrer do processo ensino e aprendizagem sendo sempre flexível quanto a sua metodologia já preexistente.

A metodologia de coleta de dados lançara mão com base na observação com os alunos do ensino fundamental. Essa pesquisa será desenvolvida em duas fases.

Em primeiro lugar, haverá levantamento de dados bibliográficos sobre o tema leitura e escrita. O uso da leitura em sua vida cotidiana, preferencias, etc. Na segunda fase, será usada as teorias e a metodologia da observação visando identificas a necessidade de leitura em seu ambiente familiar, profissional com coletas de dados dobre inclinações de leitura do aluno e finalmente, será mostrada a competição do conhecimento produzido, seguido da apresentação dos resultados da escola, conforme gráficos abaixo. 
Gráfico 1 - Percentual de alunos por nível de proficiência.

\section{Gráficos do Percentual de Alunos por Nível de Proficiência}

\section{No Estado:}

Língua Portuguesa - $4^{\mathrm{a}}$ série / 50 ano EF

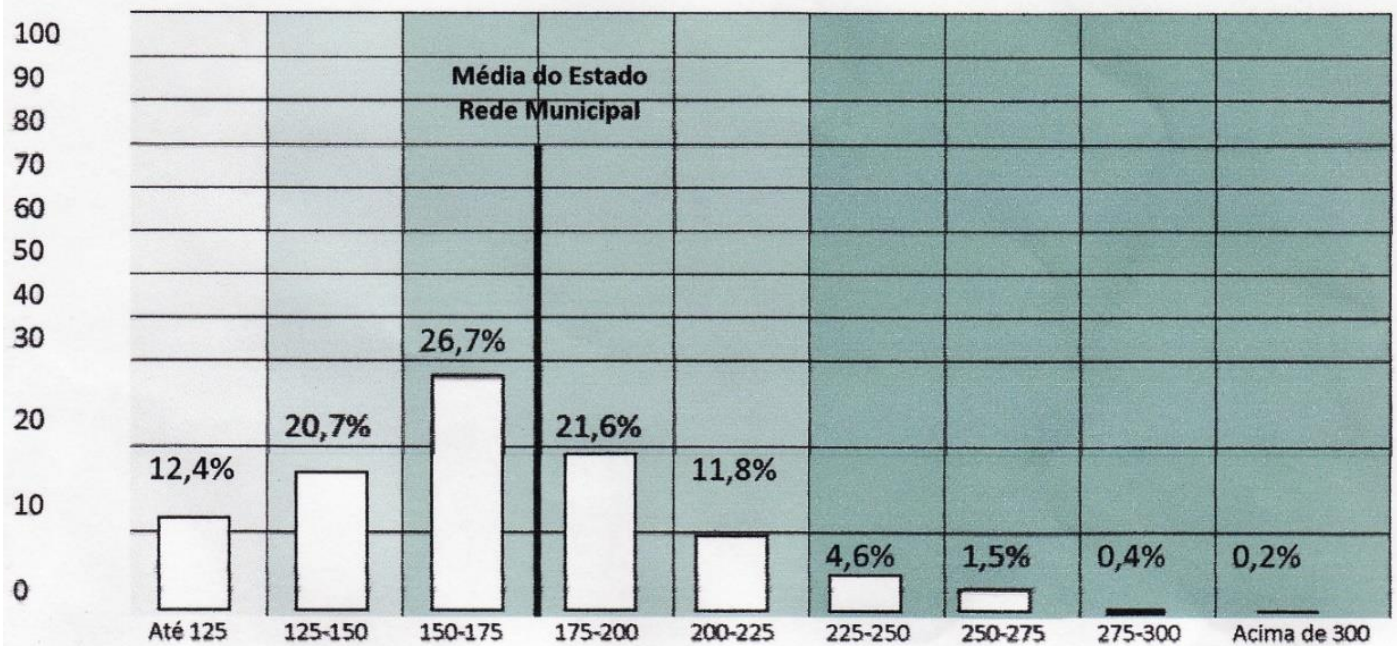

\section{ESCOLA DE ENSINO FUNDAMENTAL DA ZONA URBANA}

Língua Portuguesa $-4 \underline{a}$ série / $5 \stackrel{2}{\text { ano }} \mathrm{EF}$

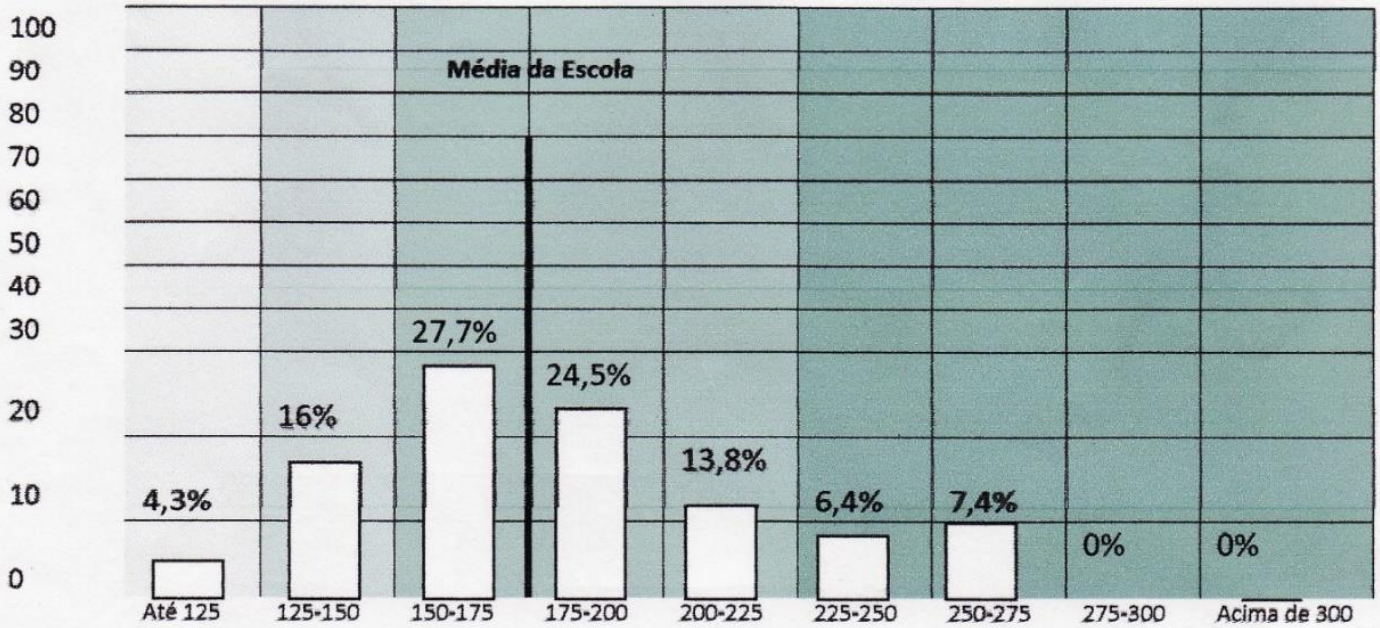

Legenda: 
No Brasil pode-se constatar que quase um terço da população possui baixo índice de letramento. Entre os jovens e adultos, considerando-se aqueles que têm mais de 15 anos, cerca de $13 \%$ são analfabetos, ainda que um terço já tenha passado pelo ensino fundamental. Entre as crianças, mais da metade das que chegam a $4^{\mathrm{a}}$ série não tem rendimentos adequado em leitura. Quase 30\% dessas crianças não sabem ler.

Uma devida Escola de Ensino Fundamental da Zona Urbana tem como estratégia valorizar a clientela, proporcionando a qualidade e a excelência em tudo que faz.

Deixa transparente com orgulho uma comunicação honesta e aberta, incentiva a criatividade e inovação para que frutifiquem resultados positivos para todos os desafios, tem como visão uma escola de referências, voltada para o desenvolvimento de sociedade e primando pela educação.

A referida escola tem como missão oferecer aos alunos uma prática pedagogia de preparação para o exercício da cidadania, dando-lhes subsídios para o desafio do mundo, tendo como objetivo melhorar o processo do ensino aprendizagem, elevar o desempenho acadêmico e instigar a participação dos pais para o compromisso com a aprendizagem dos filhos.

\section{Considerações Finais}

Este trabalho é fruto de várias pesquisas de caráter bibliográfico e de um projeto pedagógico consolidado na clientela do Ensino fundamental.

Constatou-se que apesar do índice de aprovação ser elevado no ano de 2009 ainda existe um número significativo de alunos com deficiência na aprendizagem em relação a leitura e a escrita no ano de 2015, mas ainda é possível trabalhar para superar as dificuldades do ensinoaprendizagem. Pode-se afirmar que a deficiência supracitada resulta em tal situação, provocando o empobrecimento vocabular e discursivo do educando, criando no mesmo uma barreira que dificulta a má produção escrita.

Compreendendo as necessidades do educando, como também de professores e profissionais da educação em relação das mudanças, deficiências e dificuldades encontradas no referido assunto. 
Convictos de que os objetivos foram alcançados e as metas plenamente atingidas faz-se necessário compreender a importância das teorias e dos métodos de Piaget e Vygotsky e sua contribuição para o ensino-aprendizagem, despertando o educando a reflexão, análise, valorizando, apreciando, agindo, sentindo e valorizando o outro, adquirindo segurança na argumentação própria da capacidade de pensar na valorização da linguagem e na expressão de pensamento.

Pode-se dizer que a sociedade necessita de pessoas pensantes, críticos, ativos e participativos, comprometidos, capazes de dominar e produzir seus conhecimentos de acordo com a visão de mundo ou com o nível que está inserido.

\section{Referências}

CAGLIARI, Luiz Carlos. Alfabetização e linguística. São Paulo: Scipione, 1991.

FREIRE, Paulo. A importância do ato de ler. 27. ed. São Paulo: Cortez, 1992.

SILVA, Ezequiel Theodoro da. O ato de ler: fundamentos psicológicos para uma nova pedagogia da leitura. 3. ed. São Paulo: Cortez, 1988.

Educação e mudança. 26. ed. Rio de Janeiro: Paz e Terra, 2002.

Bibliografia - VYGOTSKY, Leu S. 1989. A Formação Social da mente. São Paulo, Mantim Fontes

PALANGANA, Isilda C. 1989. Desenvolvimento e Aprendizagem: Piaget e Vygotsky: A Relação do Social numa perspectiva Internacionalista.

PALACIOS, Jesus 1995. Introdução à psicologia Evolutiva: História, conceitos Básicos e Metodologia. 9-26. O Desenvolvimento após a Adolescencia.

Como citar este artigo (Formato ABNT):

COSTA, Francisca Ilka O. B.; CUNHA, Francisco Roberto B. Leitura e Escrita. Id on Line Revista Multidisciplinar e de Psicologia, Maio de 2017, vol.11, n.35, p.405-423. ISSN: 1981-1179.

Recebido: 23.05.2017

Aceito: 28.05 .2017 